\title{
Combined effect of 'biodiesel, ethanol, exhaust gas recirculation and magnetization of fuel' on the performance and emission parameters of diesel engine.
}

DOI : 10.36909/jer.12065

Ajay Chandravanshi", Shrikant Pandey, Rakesh K. Malviya

Department of Mechanical Engineering, Shri Vaishnav Vidhyapeeth Viswavidyalaya, Indore 453111, Madhya Pradesh, India

*Corresponding Author: chandravanshiajay87@gmail.com

\begin{abstract}
Utilization of biodiesel as alternative fuel results in higher emission of oxides of nitrogen (NOx) and reduced performance parameters. Exhaust gas recirculation (EGR) is a great technology to control the emission of NOx, but use of EGR reduces the performance parameters of diesel engines. Oxidative addition and magnetization of fuel help to make the combustion complete. In the present investigation, Jatropha biodiesel has been used with diesel in the form of a blend having 20\% biodiesel (BD20) as fuel in 4-stroke, direct ignition, diesel engine. 5\% Ethanol (E5) has been used as additive along with biodiesel blends and 10\% EGR. The magnetization of fuel (MF) has been done with the help of a permanent magnet having strength of 3000 gauss. The results of this investigation show that BD20 is beneficial as fuel for reducing emissions like Carbon Mono-oxide, Hydro-Carbon, and smoke but it reduces Brake Power and Brake Thermal Efficiency. BD20E5 gives better performance parameters than the BD20, but the emission of HC
\end{abstract}


increases slightly. $10 \%$ EGR reduces NOx emission with a small cost of performance parameters but with MF performance and emission parameters were improved.

Keywords: Biodiesel; Diesel Engine; Ethanol; Exhaust gas recirculation; Fuel Magnetization.

\section{INTRODUCTION}

All nations of the world are confronting the issues of exhaustion of petroleum fuel and contamination of the atmospheric air because of the creation of hurtful gases (Bhale et al., 2009; Madiwale et al., 2018; Srinidhi et al., 2018). Looking for elective fuel biodiesel can turn into a key factor to full fill the world's vitality request and diminish the toxic outflows (Madiwale et al., 2018; Kumar et al., 2018; Srinidhi et al., 2019; Srinidhi et al., 2020; Srinidhi et al., 2021). Biodiesels are methyl ester or ethyl ester of plant oil, for the most part delivers from transesterification of eatable and non-eatable oil (Bhale et al., 2009; Kumar et al., 2018; Srinidhi et al., 2020). With the utilization of biodiesel as fuel in compression ignition engine execution factors were diminished somewhat, while outflows of $\mathrm{HC}$, and $\mathrm{CO}$ reduces when contrasted with 100\% diesel (D) yet emanation of NOx increases (Ashok et al., 2017; Ashok et al., 2018; Srinidhi et al., 2018; Srinidhi et al., 2019; Srinidhi et al., 2020; Srinidhi et al., 2021). As per some investigation outflow of Carbon di Oxide $\left(\mathrm{CO}_{2}\right)$ is additionally higher with biodiesel as fuel in a compression ignition engine, when contrasted with diesel (Srinidhi et al., 2021).

Ethanol is one of the most common fuel additive, which provide improved mixing of fuel -air blend and promote the combustion of Jatropha biodiesel. Blends of alcohol and biodiesel try to modify the thermo-material properties of methyl ester (Srinidhi et al., 2020). Ethanol has been used to reduce density and viscosity of biodiesel blends, ethanol is also rich in oxygen content which makes the atomization of biodiesel better due to it's good evaporative characteristic. (Imtenan et al., 2014). Utilizing ethanol or bioethanol as an added substance with biodiesel 
brings about higher BTE, BSFC, and HC outflow while lower CO, NOx, and smoke emanation when contrasted with biodiesel (How et al., 2014; Imtenan et al., 2014; Misra and Murthy, 2011).

Recirculation of exhaust gases is a procedure to lessen unsafe emanations, explicitly for decreasing the discharge of oxides of nitrogen (NOx). In this, part of fumes is sent back to the inlet channel, which blends in with incoming air, and oxygen contained in it and utilized for the burning of fuel (Srinidhi et al., 2019; Srinidhi et al., 2020). When EGR is utilized with ethanol as added substance, while utilizing biodiesel mixes as fuel, BTE is lower and BSFC is higher (Yasin et al., 2015; Sakhare et al., 2016; Solaimuthu et al., 2015). The outflows of HC, $\mathrm{CO}$, and $\mathrm{CO}_{2}$ are seen as marginally higher with the utilization of EGR and biodiesel as fuel (Yasin et al., 2015; Yasin et al., 2017; Srinidhi et al., 2019).

When the charge is made to enter the burning chamber, then mixing and realignment of molecules with oxygen are left. The realignment of hydrocarbon chains with oxygen and ionization of particles are necessary conditions for improved combustion. This can be achieved by the application of magnetic field on fuel piping, before the ignition chamber as shown in fig. 1 (a) (Sahoo and Jain, 2019). Magnetization changes the hydrocarbon molecules from the larger bundles to the smaller group with higher space for oxygen needed for improved combustion, which improves the combustion and declined outflow of NOx and CO for the most part (Wahhab et al., 2017; Sahoo and Jain, 2019). Application of magnetic field on fuel makes the bond between oxygen and hydrocarbon much stronger and increases the enthalpy of combustion as shown in fig. 1 (b) (Wahhab et al., 2017). Hydrogen atom is having dipole moment and charged positive or negative with the presence of proton and electron respectively. Due to the nucleus rotation under the effect of magnetic field hydrogen becomes paramagnetic or diamagnetic as 
shown in fig.1 (c). Polarization of fuel brings higher BTE and lower BSFC with the lower emanation of $\mathrm{HC}, \mathrm{CO}, \mathrm{CO}_{2}$, and NOx (Wahhab et al., 2017; Sahoo and Jain, 2019).

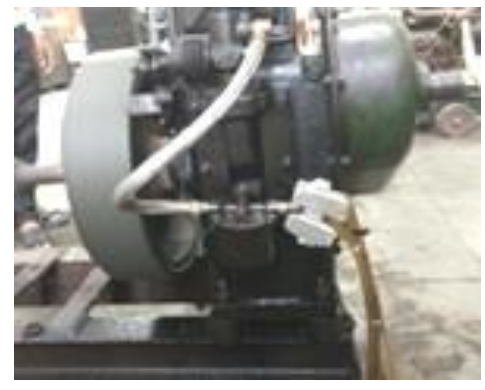

(a)

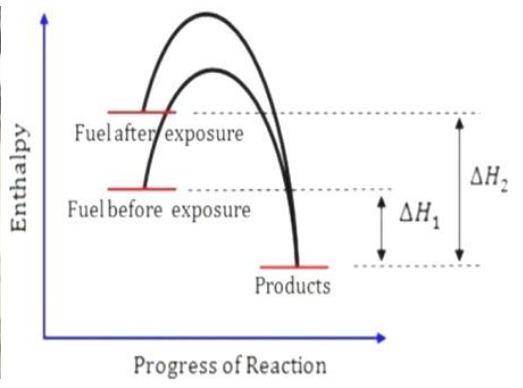

(b)

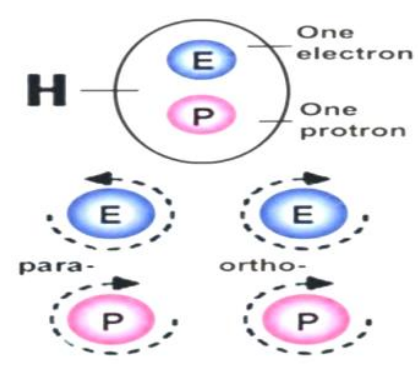

(c)

Figure 1.(a) Fuel Magnetization (Sahoo and Jain, 2019), (b), Effect of Magnetization on Combustion Energy (Wahhab et al., 2017)

(c) Atomic Orientation (Wahhab et al., 2017)

\section{MATERIALS AND METHODOLOGY}

In the present investigation fuel used is the blend of biodiesel of jatropha oil and diesel. Jatropha methyl ester has been collected from Hindustan biodiesel Ujjain, Madhya Pradesh, India. Fuel blends prepared for this experimentation are Pure diesel (D), $80 \%$ diesel with $20 \%$ biodiesel (BD20) and $75 \%$ diesel $+20 \%$ biodiesel $+5 \%$ ethanol (BD20E5). Ethanol has been taken from Mahakal Institute of Pharmacy Ujjain, Madhya Pradesh, India.

\section{Test Fuel}

Density and viscosity of ethanol match with those of biodiesel and it is highly soluble in biodiesel (Bhale, et al., 2009). In this research firstly, ethanol was blended with biodiesel and mixed properly. After that this blend of ethanol and biodiesel were blended with diesel and mixed again. No surfactant was used in this investigation. Table 1 shows the important chemical properties of fuel blends used during this investigation. 
Table 1.Properties of Fuel Blends.

\begin{tabular}{|c|c|c|c|}
\hline Properties & D & BD20 & BD20E5 \\
\hline Density (kg/m3) & 850 & 852.12 & 851.75 \\
\hline Calorific Value (kJ/g or MJ/kg) & 43.400 & 41.83 & 40.95 \\
\hline Viscosity (@ 40 $\left.{ }^{\circ} \mathbf{C}, \mathbf{m m} 2 / \mathbf{s}\right)$ & 3.5 & 3.72 & 3.65 \\
\hline $\begin{array}{c}\text { Latent Heat of Vaporization } \\
(\mathbf{k J} / \mathbf{k g})\end{array}$ & 250 & 240 & 270 \\
\hline Cetane No & 47 & 47.8 & 45.81 \\
\hline
\end{tabular}

\section{Experimental Setup}

The experimental setup consists of a four-stroke, single cylinder, vertical diesel engine having a constant compression ratio of 17.5. The schematic diagram of the complete set up used for this investigation is shown in fig. 2 .

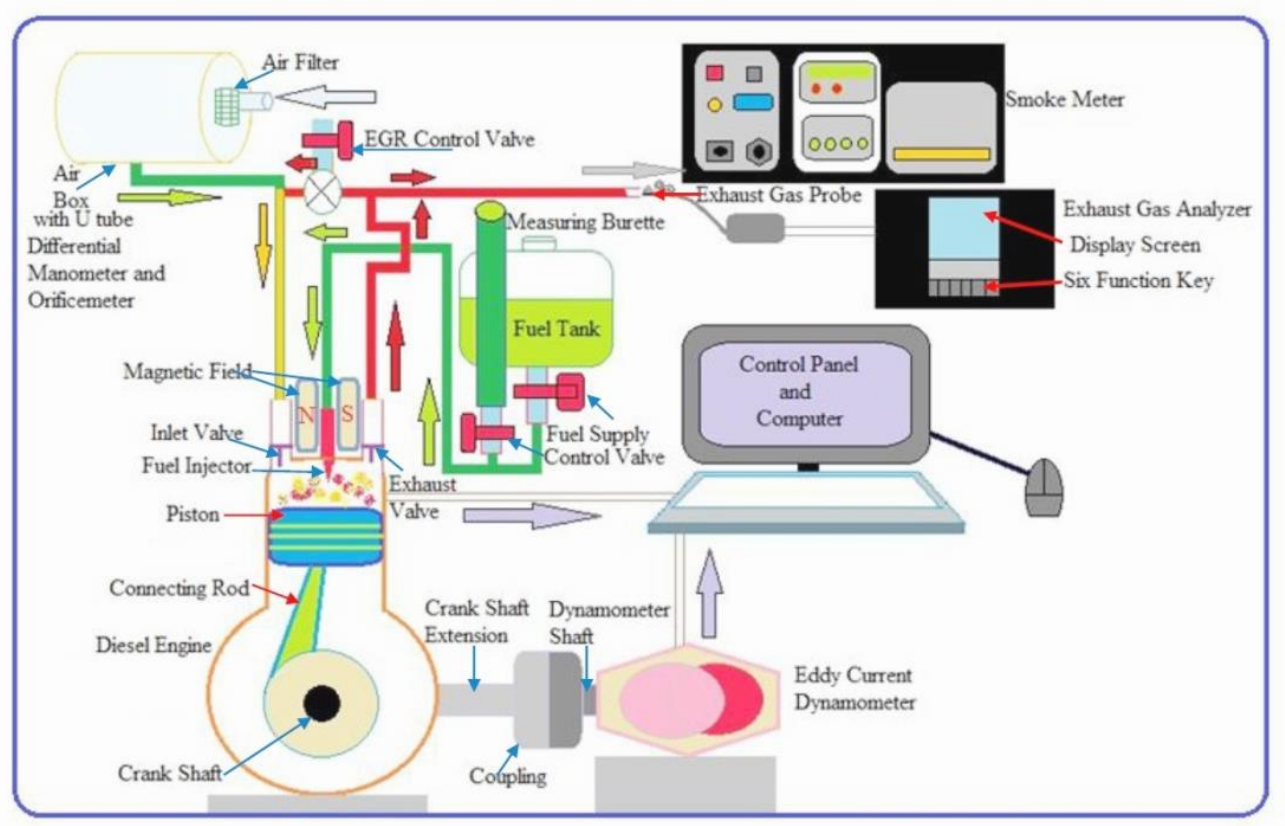

Figure 2. Schematic diagram of the experimental setup

No governor has been used in this research. Speed was changing with change in load and can be measured with the help of Tachometer. Maximum and minimum speeds were noticed between 1300 and 1600 RPM respectively. Brake power depends upon speed and torque produced, which is the reason behind the change in $\mathrm{BP}$ and given by: 


\section{$\mathrm{BP}=2 \pi \mathrm{NT} / 60$ (Solaimuthu, et al., 2015)}

Where $\mathrm{N}$ is speed in RPM and $\mathrm{T}$ is the torque produced in $\mathrm{N}-\mathrm{m}$.

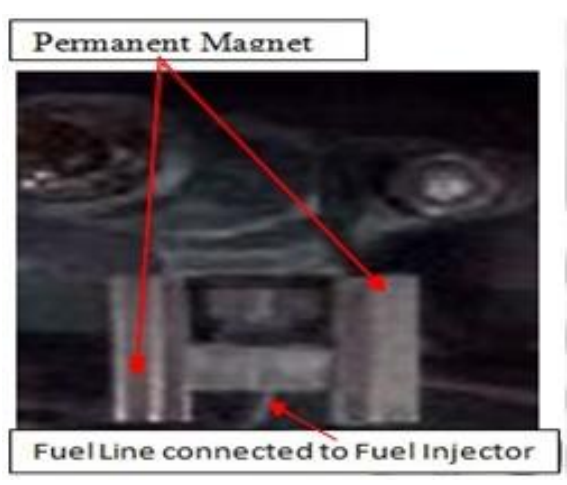

(a)

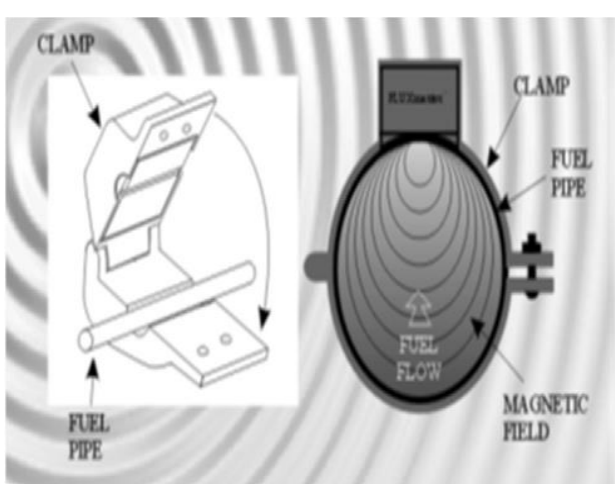

(b)

Figure 3.(a) Fuel Magnetization, (b) Magnetization of fuel (Wahhab, et al., 2017)

Magnetization of fuel has been done by attaching permanent magnet on fuel line, just before injection of fuel blend into the cylinder as shown in fig. 3(a). Magnetic field can also be produced with the help of electric magnet as shown in fig. 3(b) (Wahhab, et al., 2017, Sahoo and Jain 2019).U tube differential manometer and orifice meter have been used for flow measurement of air. Readings for the consumption of fuel is taken from the attached burette. Thermocouples have been used for temperatures at different points and temperatures were shown on the control panel. Air-box, air filter, eddy current dynamometer and magnet of 3000 gauss are the devices used in this study. Rota-meters have been used for the discharge calculations of cooling water for engine and dynamometer. Observations have been taken with no load, $5 \mathrm{~kg}$, $10 \mathrm{~kg}, 15 \mathrm{~kg}$ and $20 \mathrm{~kg}$ load with various fuel blends and with various conditions. Table 2 shows the specifications of the diesel engine. Table 3 shows the uncertainties in the measurements of various parameters calculated by Root Sum Square method (Sahoo and Jain, 2019). Calculated value of overall uncertainty is 3.76 . 
Table 2. Technical specifications of the Diesel Engine.

\begin{tabular}{|c|c|}
\hline Engine & Kirloskar tv1 \\
\hline Bore x stroke & $87.5 \mathrm{~mm}$ x110mm \\
\hline Cubic Capacity & $661 \mathrm{~cm} 3$ \\
\hline Compression Ratio & $17.5: 1$ \\
\hline Rated output: & $5.2 \mathrm{kw}$ at $1500 \mathrm{rpm}$ \\
\hline Fuel injector pressure & $20-25 \mathrm{Mpa}$ \\
\hline Injection timing & 2 \\
\hline No of valves & 23 degree before Top Dead Centre (TDC) \\
\hline Valve timing & 4.5 degree \\
\hline Inlet valve opens After Bottom Dead Centre \\
(BDC) & 35.5 degree \\
\hline Exhaust valve opens before BDC & 35.5 degree \\
\hline Governor type & 4.5 degree \\
\hline Fuel injection type & Mechanical, centrifugal type \\
\hline
\end{tabular}

Table 3. Uncertainty Analysis of various measuring parameters

\begin{tabular}{|c|c|c|c|}
\hline Device/ Parameter & Range & Accuracy & Uncertainty \\
\hline Carbon Monooxide & 0 to $10 \%$ by vol. & $0.01 \%$ by vol. & \pm 0.2 \\
\hline Carbon Dioxide & 0 to $20 \%$ by vol. & $0.1 \%$ by vol. & \pm 1 \\
\hline Oxides of Nitrogen & 0 to $4000 \mathrm{ppm}$ vol. & $1 \mathrm{ppm} \mathrm{vol}$. & \pm 2 \\
\hline Hydrocarbon & 0 to $20000 \mathrm{ppm}$ vol. & $1 \mathrm{ppm} \mathrm{vol}$. & \pm 0.3 \\
\hline Exhaust Gas Temperature & 0 to $500^{\circ} \mathrm{C}$ & $\pm 1^{\circ} \mathrm{C}$ & \pm 1.4 \\
\hline Flow Meter & 1 to $20 \mathrm{cc}$ & $\pm 0.1 \mathrm{cc}$ & \pm 0.6 \\
\hline Piezo sensor & 0 to $5000 \mathrm{psi}$ & $\pm 1 \mathrm{bar}$ & \pm 1.2 \\
\hline Smoke & 0 to $100 \%$ opacity in $\%$ & $\pm 1 \%$ full scale reading & \pm 1.5 \\
\hline Engine speed & 250 to $8000 \mathrm{rpm}$ & $10 \mathrm{rpm}$ & \pm 0.1 \\
\hline Time (Stop watch) & 999 minutes $/ 59.9 \mathrm{~s}$ & $\pm 0.1 \mathrm{~s}$ & \pm 1 \\
\hline U-tube manometer & 0 to $500 \mathrm{~mm}$ & $\pm 1 \mathrm{~mm}$ & \pm 1 \\
\hline Burette & 0 to $100 \mathrm{cc}$ & $\pm 1 \mathrm{cc}$ & \pm 1 \\
\hline
\end{tabular}

\section{RESULT AND DISCUSSION}

\section{Performance Parameters}

Fig. 4 (a), (b) and (c) show the variation in performance parameters like BP, BTE and BSFC with various blends and conditions. BP and BTE are slightly lesser with BD20 as compared to diesel fuel. BP is lower due to lower calorific value, higher density and higher viscosity of BD20 than D, which reduces atomization and combustion efficiency (Ahmed et al., 2014; Imtenan et 
al., 2014). Reductions in BP and BTE have been reduced by using BD20E5 due to imroved atomization and combustion efficiency (Misra and Murthy, 2011; Imtenan et al., 2014). BTE further increases with BD20E5 + MF as compared to BD20. Fuel Particles are dispersed and devided finely, which results in active interlocking of oxygen with fuel molecules and increases the degree of complete combustion (Sahoo and Jain, 2019). Maximum decrease in BTE with $\mathrm{BD} 20, \mathrm{BD} 20 \mathrm{E} 5, \mathrm{BD} 20+\mathrm{MF}$ and BD20E5+MF with respect to diesel are $11.60 \%, 10.83 \%$, $10.83 \%$ and $6.52 \%$ respectively. But with the use of EGR, BP and BTE are lower than all tried blends and techniques, due to insufficient oxygen present in the combustion chamber resulting in incomplete burning (Yasin et al., 2015). The highest reduction in BP and BTE with BD20E5+10\%EGR noticed are $7.88 \%$ and $22.68 \%$ respectively with reference to diesel. These decreases in BP and BTE have been reduced with BD20E5+10\%EGR+MF to $6.22 \%$ and $17.72 \%$ respectively. Presence of ionized particles in combustion chamber improves the combustion hence increases the brake power (Barna and Lelea, 2017).

It can be seen that BSFC increases with the use of BD20 due to lower heating value of BD (Ashok, et al. 2017). BSFC further increases with the use of EGR due to lower oxygen content during combustion (Yasin et al., 2015). The highest relative increase in BSFC is $19.52 \%$ at medium load with BD20 as compared to diesel. With BD20E5, BD20+MF and BD20E5+MF this increase is $16.02 \%, 15.35 \%$ and $9.53 \%$ respectively as compared to BD20. Improved atomization and combustion quality result in slight decrease in BSFC with additive (Imtenan et al., 2014). But as $10 \%$ EGR is utilized along with BD20E5 this increment goes up to $18.01 \%$. Utilizing BD20E5+10\%EGR+MF brings down this increase to $11.75 \%$. Reduced surface tension and increased energy with magnetic field are the reason for reduced BSFC with fuel magnetization (Wahhab et al., 2017). 


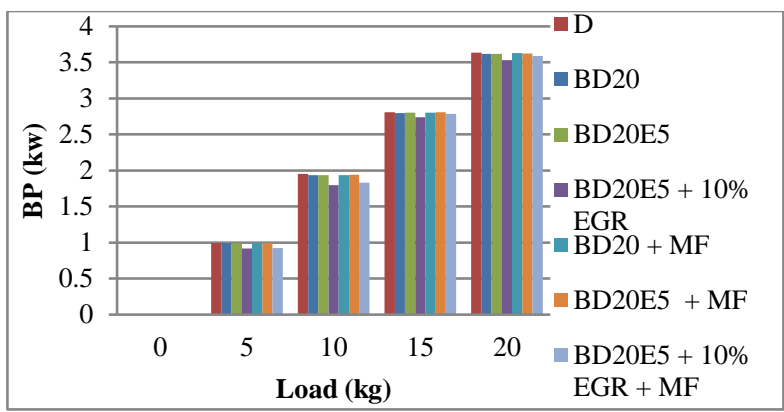

(a)

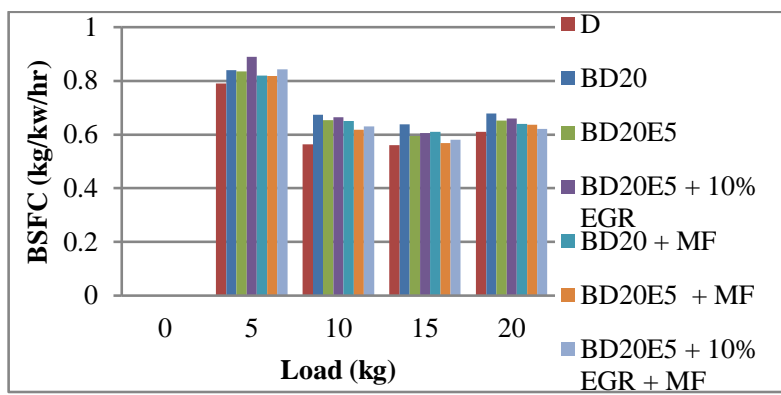

(b)

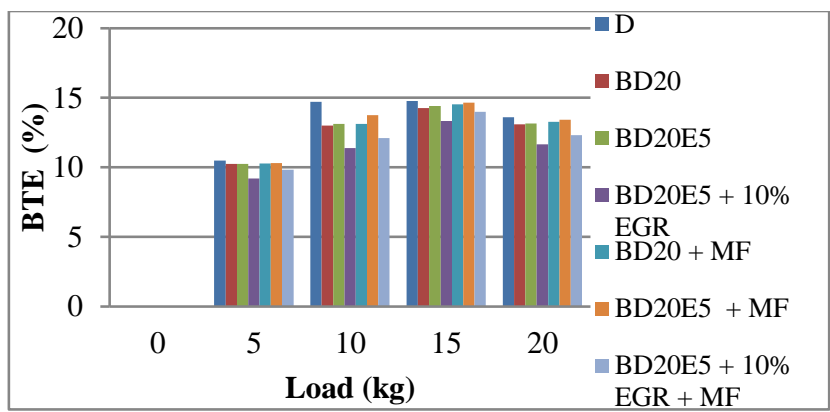

(b)

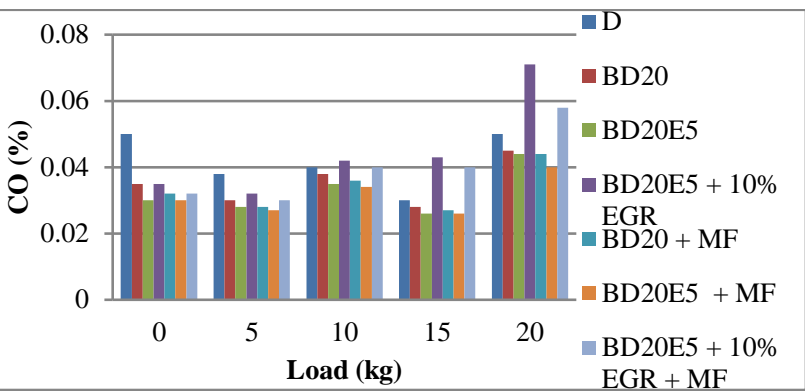

(d)

Figure 4.Variation in (a) BP, (b) BTE, (c) BSFC and (d) CO emission with various blends and operating conditions.

\section{Emissions}

Fig. 4 (d), Fig. 5 (a), (b), (c) and (d) show the variations in emissions of $\mathrm{CO}, \mathrm{HC}, \mathrm{NOx}, \mathrm{CO}_{2}$ and smoke with various blends and operating conditions. Emission of $\mathrm{CO}$ decreases with the use of BD20 as compared to diesel due to higher cetane number and inherent oxygen content (Ashok et al., 2017), CO emission further reduces with the use of BD20E5 due to increased level of oxygen in fuel blend (Imtenan et al., 2014). There is a decrease in HC outflow with the use of BD20 and BD20E5 as compared with diesel. But HC emission is a little higher with BD20E5 than with BD20 and these results are inline with Bhale et al., 2009. CO emission is much lower with the use of BD20E5+MF due to inrceased oxygen availability and improved combustion (Sahoo and Jain, 2019). But the emissions of CO and HC increase with the use of EGR due to replacement of oxygen by exhaust gases and incomplete combustion (Yasin et al., 2015) and controlled by MF verified with Sahoo and Jain, 2019. Maximum decrease in CO with BD20, BD20E5, BD20+MF 
and $\mathrm{BD} 20 \mathrm{E} 5+\mathrm{MF}$ as compared to diesel are $30 \%, 40 \%, 36 \%$ and $40 \%$. The maximum increase in CO and $\mathrm{HC}$ emissions with BD20E5+10\%EGR are $40 \%$ and $23.40 \%$, which were brought down to $36 \%$ and $14.89 \%$ with the use of BD20E5+10\%EGR+MF.

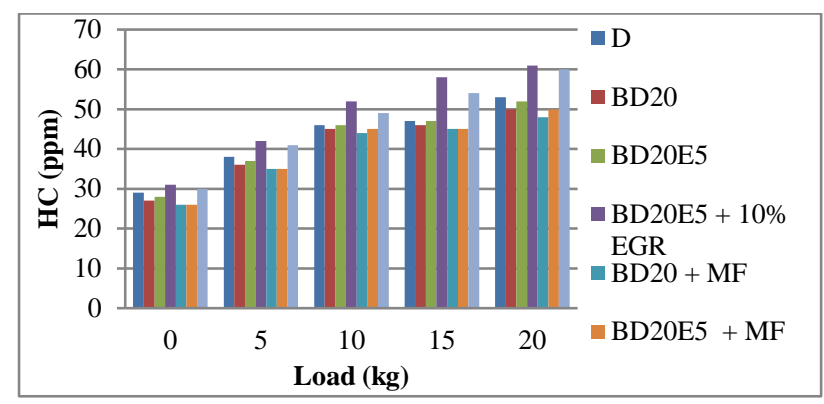

(a)

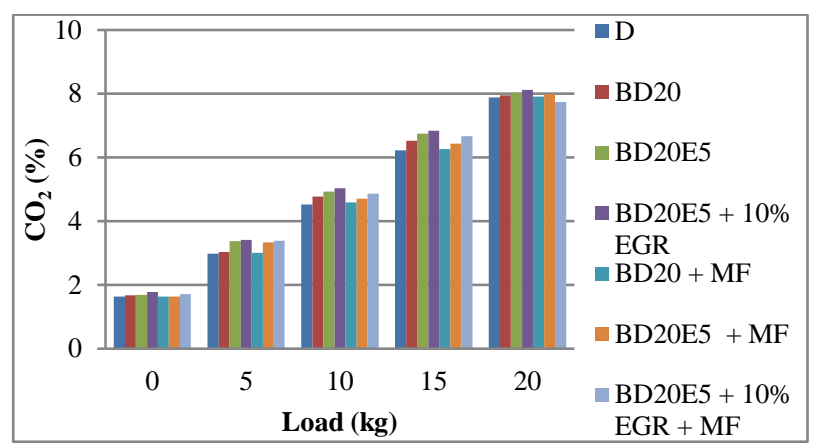

(c)

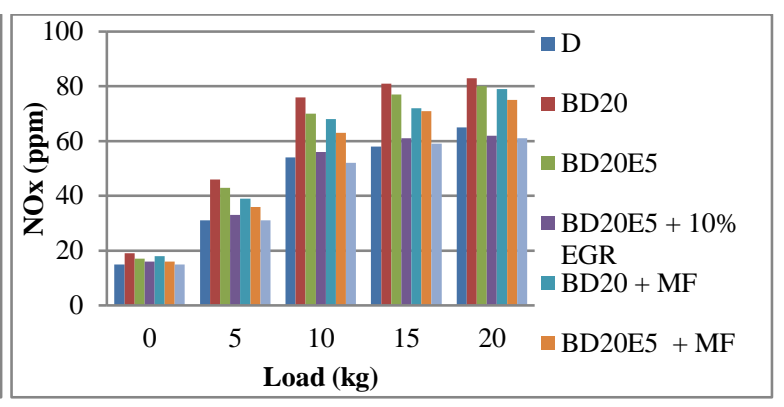

(b)

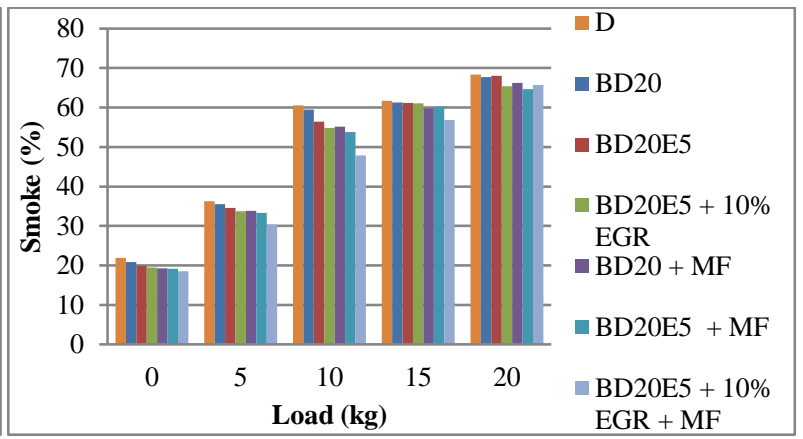

(d)

Figure 5.Variations in (a) $\mathrm{HC}$, (b) $\mathrm{NOx}$, (c) $\mathrm{CO}_{2}$ and (d) smoke emission with various blends and operating conditions.

The emission of NOx increases with the use of biodiesel up to $48.38 \%$ due to higher oxygen content in $\mathrm{BD}$, which results in elevated oxidation, increased EGT and higher NOx emission (Ahmed et al., 2014). EGR reduces the temperature by increasing total heat capacity of gases in combustion chamber (Yasin et al., 2015). At higher loads with BD20E5+10\%EGR, a decrease of $4.61 \%$ in the relative percentage of NOx has been noted. Ethanol addition reduces the average temperature of working gas due to higher latent heat of vaporization and lower heating value (Imtenan et al., 2014). NOx is further reduced upto 6.15\% using BD20E5+10\%EGR+MF with 
the dispersed fuel arrangement achieved by fuel magnetization validated with Wahhab et al., 2017.

The emission of $\mathrm{CO}_{2}$ is a little higher with various blends as compared to diesel, due to the complete combustion of fuel and conversion of $\mathrm{CO}$ into $\mathrm{CO}_{2}$ verified with Yasin et al. 2015 and 2017. The highest percentage of $\mathrm{CO}_{2}$ increase goes up to $14.76 \%$ with $\mathrm{BD} 20 \mathrm{E} 5+10 \% \mathrm{EGR}$ at a lower load. This increase has been brought down to $13.75 \%$ with the use of BD20E5+10\%EGR+MF verified with Sahoo and Jain 2019. With biodiesel and ethanol, smoke emission reduces due to present of higher oxygen to burn fuel (How et al. 2014). Effect of producing higher smoke with EGR was suppressed with ethanol and fuel magnetization. It may be due to proper mixing and improved combustion takes place with high oxygen content and ionization of fuel molecules (Thiyagarajan et al., 2018).

\section{CONCLUSION}

Use of biodiesel introduces penalty in the form of lower BP, lower BTE, higher BSFC, and higher NOx emission. Using biodiesel also reduces emissions like $\mathrm{CO}, \mathrm{HC}$ and smoke outflow as compared to diesel. The average decrease in BP, with BD20E5+10\%EGR+MF blend was 3.10\%, average increase in BSFC was $4.80 \%$, average decrease in BTE was $7.75 \%$, average decrease in $\mathrm{CO}$ emission was $1.54 \%$, average increase in $\mathrm{HC}$ emission was $9.19 \%$, average decrease in emission of NOx was $1.62 \%$ and the average decrease in smoke outflow was $12.86 \%$ as compared with diesel. Based on the results and discussion conclusion can be made, that Biodiesel, ethanol and EGR could be used in lower quantity to maintain optimum level of performance and emission parameters along with fuel magnetization. 


\section{REFERENCES}

Ahmed, S., Hassan, M.H., Kalam, M.A., Rahman, S.M.A., Abedin, M.J., \& Shahir, A. 2014. An experimental investigation of biodiesel production, characterization, engine performance, emission and noise of Brassica juncea methyl ester and its blends. Journal of Cleaner Production, 79: 74-81 http://dx.doi.org/10.1016/j.jclepro.2014.05.019

Ashok, B., Nanthagopal, K., Jeevanantham, A.K., Bhowmick, P., Malhotra, D., \& Agarwal, P. 2017. An assessment of calophyllum inophyllum biodiesel fuelled diesel engine characteristics using novel antioxidant additives. Energy Conversion and Management, 148: 935-943. https://doi.org/10.1016/j.enconman.2017.06.049

Ashok, B., Nanthagopal, K., \& Vignesh, D.S. 2018. Calophyllum inophyllum methyl ester biodiesel blend as an alternate fuel for diesel engine application. Alexandria Engineering Journal, 57: 1239-1247. https://doi.org/10.1016/j.aej.2017.03.042

Bhale, P.V., Deshpande, N.V., \& Thombre, S.B. 2009. Improving the low temperature properties of biodiesel fuel. Renewable Energy, 34: 794-800. https://doi.org/10.1016/j.renene.2008.04.037

How, H.G., Masjuki, H.H., Kalam, M.A., \& Teoh, Y.H. 2014. Engine performance, emission and combustion characteristics of a common-rail diesel engine fuelled with bioethanol as a fuel additive in coconut oil biodiesel blends. Energy Procedia, 61: 1655-1659. doi: 10.1016/j.egypro.2014.12.185

Imtenan, S., Masjuki, H.H., Varman, M., Arbab, M.I., Sajjada, H., Fattah, I.M.R., Abedin, M.J., \& Hasib, A.S.M. 2014. Emission and performance improvement analysis of biodieseldiesel blends with additives. Procedia Engineering, 90: 472-477. https://doi.org/10.1016/j.proeng.2014.11.759 
Imtenan, S., Masjuki, H.H., Varman, M., Kalam, M.A., Arbab, M.I., Sajjad, H., \& Rahman, S.M.A. 2014. Impact of oxygenated additives to palm and jatropha biodiesel blends in the context of performance and emissions characteristics of a light-duty diesel engine. Energy Conversion and Management, 83: 149-158. https://doi.org/10.1016/j.enconman.2014.03.052

Kumar, M.V., Babu, A.V., \& Kumar, P.R. 2018. The impacts on combustion, performance and emissions of biodiesel by using additives in direct injection diesel engine. Alexandria Engineering Journal, 57: 509-516. https://doi.org/10.1016/j.aej.2016.12.016

Madiwale, S., Karthikeyan, A., \& Bhojwani, V. 2018. Properties investigation and performance analysis of a diesel engine fuelled with Jatropha, Soybean, Palm and Cottonseed biodiesel using Ethanol as an additive. Materials Today: Proceedings, 5: 657-664. https://doi.org/10.1016/j.matpr.2017.11.130

Misra, R.D., \& Murthy, M.S. 2011. Blending of additives with biodiesels to improve the cold flow properties, combustion and emission performance in a compression ignition engine- $\mathrm{A}$ review. Renewable and Sustainable Energy Reviews, 15: 2413-2422. https://doi.org/10.1016/j.rser.2011.02.023

Sahoo, R.R., \& Jain, A. 2019. Experimental analysis of nanofuel additives with magnetic fuel conditioning for diesel engine performance and emissions. Fuel, 236: 365-372. https://doi.org/10.1016/j.fuel.2018.09.027

Sakhare, N.M., Shelke, P.S., \& Lahane, S. 2016. Experimental Investigation of Effect of Exhaust Gas Recirculation and Cottonseed B20 Biodiesel Fuel on Diesel Engine. Procedia Technology, 25: 869-876. doi: 10.1016/j.protcy.2016.08.195 
Solaimuthu, C., Ganesan, V., Senthilkumar, D., \& Ramasamy, K.K. 2015. Emission reductions studies of a biodiesel engine using EGR and SCR for agriculture operations in developing $\quad$ countries. $\quad$ Applied $\quad$ Energy, $\quad 138: \quad 91-98$. https://doi.org/10.1016/j.apenergy.2014.04.023

Srinidhi, C., Madhusudhan, A., \& Channapattana, S.V. 2019. Effect of NiO nanoparticles on performance and emission characteristics at various injection timings using biodieseldiesel blends. Fuel, 235: 185-193. https://doi.org/10.1016/j.fuel.2018.07.067

Srinidhi, C., Madhusudhan, A., \& Channapattana, S.V. 2019. Comparative analysis of exhaust gas recirculation and nanoparticles on the performance and emission of diesel engine fuelled with neem biodiesel blend. International Journal of Ambient Energy, ISSN: 01430750 (Print) 2162-8246 (Online). https://doi.org/10.1080/01430750.2019.1636876

Srinidhi, C., Madhusudhan, A., \& Channapattana, S.V. 2019. Parametric studies of CI engine at various injection strategies using biodiesel blended nanoparticles as fuel. International Journal of Ambient Energy, ISSN: 0143-0750 (Print) 2162-8246 (Online). https://doi.org/10.1080/01430750.2019.1630303

Srinidhi, C., Madhusudhan, A., Channapattana, S.V., \& Gawali, S.V. 2020. Comparitive investigation of performance and emission features of methanol, ethanol, DEE, and nanopartilces as fuel additives in diesel-biodiesel blends. Heat Transfer, 2020; 1-19. DOI: 10.1002/htj.21997

Srinidhi, C., Madhusudhan, A., Channapattana, S.V., Pawar, A.A., Gawali, S.V., \& Hole, J.A. 2020. The effect of nickel oxide nano-additives in azadirachta indica biodiesel-diesel blend on engine performance and emission characteristics by varying compression ratio. Sustainable Energy. https://doi.org/10.1002/ep.13514 
Srinidhi, C., Panshetty, S., Madhusudhan, A., \& Channapattana, S.V. 2020. Optimization of neem biodiesel blend and injection pressure of CI engine. Advances in Structures, Systems and Materials. https://doi.org/10.1007/978-981-15-3254-2_20

Srinidhi, C., Madhusudhan, A., Channapattana, S.V., Gawali, S.V., Aithal, K. 2021. RSM based parameter optimization of CI engine fuelled with nickel oxide dosed azadirachta indica methyl ester. Energy, 234: 121282. https://doi.org/10.1016/j.energy.2021.121282

Thiyagarajan, S., Geo, V.E., Martin, L.J., \& Nagalingam, B. 2018. Effect of electrochemical conversion of biofuels using ionization system on $\mathrm{CO} 2$ emission mitigation in $\mathrm{CI}$ engine along with post-combustion system. Fuel Processing Technology, 173: 21-29. https://doi.org/10.1016/j.fuproc.2018.01.004

Wahhab, H.A.A., Al-Kayiem, H.H., Aziz, A.R.A., \& Nasif, M.S. 2017. Survey of invest fuel magnetization in developing internal combustion engine characteristics. Renewable and Sustainable Energy Reviews, 79: 1392-1399. https://doi.org/10.1016/j.rser.2017.05.121

Yasin, M.H.M., Mamat, R., Yusop, A.F., Idris, D.M.N.D., Yusaf, T., Rasul, M., \& Najafi, G. 2017. Study of a diesel engine performance with exhaust gas recirculation (EGR) system fuelled with palm biodiesel. Energy Procedia, 110: 26-31. doi:10.1016/j.egypro.2017.03.100

Yasin, M.H.M., Mamat, R., Yusop, A.F., Paruka, P., Yusaf, T., \& Najafi, G. 2015. Effects of Exhaust Gas Recirculation (EGR) on a Diesel Engine fuelled with Palm-Biodiesel. Energy procedia, 75: 30-36. https://doi.org/10.1016/j.egypro.2015.07.131 